BULLETIN Bulletin hispanique

HISPANIQUE Université Michel de Montaigne Bordeaux

120-1 | 2018

Varia

\title{
«Tiene poca ciencia de lo que es latín»
}

la prueba de imprenta como testigo del proceso editorial en el Siglo de Oro

"Il ne sait pas le latin" : la correction d'épreuves témoin du processus éditorial au Siècle d'Or

"He doesn't know any Latin": the correcting of proofs witness of the publishing process in the Spanish Golden Age

Javier Ruiz Astiz

\section{CpenEdition}

\section{Journals}

Edición electrónica

URL: https://journals.openedition.org/bulletinhispanique/5292

DOI: 10.4000/bulletinhispanique.5292

ISSN: 1775-3821

\section{Editor}

Presses universitaires de Bordeaux

\section{Edición impresa}

Fecha de publicación: 30 junio 2018

Paginación: 27-50

ISBN: 979-10-300-0298-0

ISSN: 0007-4640

\section{Referencia electrónica}

Javier Ruiz Astiz, ««Tiene poca ciencia de lo que es latín»», Bulletin hispanique [En línea], 120-1 | 2018,

Publicado el 01 enero 2022, consultado el 08 enero 2022. URL: http://journals.openedition.org/

bulletinhispanique/5292 ; DOl: https://doi.org/10.4000/bulletinhispanique.5292 


\title{
«Tiene poca ciencia de lo que es latín»: la prueba de imprenta como testigo del proceso editorial en el Siglo de Oro
}

\author{
Javier Ruiz Astiz* \\ Universidad Pública de Navarra / Nafarroako Unibertsitate Publikoa
}

Durant le Siècle d'Or espagnol, l'édition de tout ouvrage passait par plusieurs phases, de la commande auprès de l'imprimeur à la publication finale. Dans l'intervalle se déroulait un épisode clé pour la publication de l'ouvrage: la correction d'épreuves. Une procédure qui permettra de mieux connaître les subtilités éditoriales de l'époque, en particulier le rôle de l'auteur-éditeur.

Mots-clés: Juan de Ibero, Carlos de Labayen, Histoire du livre, Royaume de Navarre, Siècle d'or, Épreuve d'imprimerie.

La edición de cualquier obra durante el Siglo de Oro atravesaba por distintas etapas desde que se concertaba el encargo con el impresor hasta que finalmente era publicada. Entre medias había un proceso clave para la publicación de dichos textos, que no es otro que la corrección de pruebas. Un procedimiento que permitirá conocer mejor los entresijos editoriales de la época, en especial el papel del autor-editor.

Palabras clave: Juan de Ibero, Carlos de Labayen, Historia del Libro, Reino de Navarra, Siglo de Oro, Prueba de imprenta.

During the Spanish Golden Age, every work to be published was going through different phases, from the order to the printer till it was eventually published. In the meantime, a key process to publishing these texts took place: the correction of proofs, a procedure that will reveal the editorial intricacies of the era, especially the role of the author-editor.

Keywords: Juan de Ibero, Carlos de Labayen, Book's History, Kingdom of Navarre, Golden Age, Proof printing.

* Este trabajo se ha realizado en el marco del proyecto Biblioteca Digital Siglo de Oro 5 (BIDISO 5), con referencia: FFI2015-65779-P, financiado por el Ministerio de Economía y Competitividad del Gobierno de Espańa y el Fondo Europeo de Desarrollo Regional (FEDER) desde el 1-01-2016 hasta el 31-12-2019.

Bulletin Hispanique, Tome 120, n 1 - juin 2018 - p. 27-50. 


\section{INTRODUCCIÓN}

Los entresijos editoriales de cualquier libro se muestran inescrutables a simple vista, ya que la información que nos ofrecen, bien sea la portada, los preliminares o el propio texto de la obra resulta de escasa entidad cuando deseamos reconstruir el proceso editorial de un impreso determinado. Son los testimonios conservados en los archivos los que, por el contrario, arrojan luz sobre este tipo de cuestiones, pues gracias a distintas fuentes documentales podemos vislumbrar las peculiaridades de muchos de los textos editados en épocas pasadas.

De este modo, el testimonio sobre el que vamos a sustentar este estudio es una de las conocidas como pruebas de impresión que debieron ser práctica habitual en muchos talleres de imprenta durante los siglos XVI y XVII. Además, este hallazgo supone un rico exponente del proceso editorial en el Siglo de Oro por dos motivos. En primer lugar, se trata de un ejemplo prototípico de prueba de imprenta en el que se conservan las correcciones manuscritas introducidas por el autor, que en este caso hacía las veces también de editor. A su vez, el segundo de los motivos que hace de este descubrimiento un hecho trascendente es que se trata de una prueba que finalmente no fue más allá porque la edición del Novus et Analyticus Commentarius se vio interrumpida de forma definitiva en 1607. Por tanto, nos encontramos ante una evidencia única de un producto editorial del cual desconocíamos su existencia porque finalmente no vio la luz como un libro acabado y puesto a la venta.

No obstante, cabe resaltar que el presente artículo surge gracias a un proceso judicial que fue interpuesto en 1609 ante los Tribunales Reales de Navarra por Juan de Ibero contra Carlos de Labayen con motivo de solicitarle una cantidad económica que el primero consideraba que le debía el impresor como consecuencia de haber cesado en la edición de su libro. Este pleito conservado en el Archivo General de Navarra ${ }^{1}$ nos permitirá conocer de primera mano la trastienda de la industria editorial y, con ello, algunas de las prácticas que se solían llevar a cabo a la hora de editar un texto en un taller de imprenta. Bien es cierto que no sólo nos permite conocer la actitud del tipógrafo cuando recibía un encargo, sino que también nos ayudará a esclarecer ciertos aspectos de la figura del autor cuando actuaba como editor. Dentro de aquellos sobresale, por encima del resto, la corrección de pruebas. Dicho esto, gracias a la prueba de imprenta hallada podemos ofrecer a los estudiosos un testimonio más para ir conociendo cada día mejor la Historia del Libro.

\section{FUENTES DE ARCHIVO Y NEGOCIO EDITORIAL: RECONSTRUYENDO EL PASADO}

Cuando un investigador decide reconstruir los avatares históricos de una determinada edición no sólo debe limitarse a consultar los repertorios bibliográficos, y no porque no sean útiles, sino más bien porque no nos dan

1. A partir de ahora se citará de forma abreviada con sus siglas: AGN. 
toda la información que necesitamos. Es en los archivos donde podemos rescatar fieles testimonios de los textos impresos en los talleres de cualquier ciudad durante el Siglo de Oro. Allí debemos ir a bucear para sumergirnos, en ocasiones, en una marańa de legajos inconexos para tratar de dar luz a nuestro pasado editorial: solamente así podremos obtener una imagen lo más fidedigna posible de la Historia del Libro.

En este caso, cabe destacar que si podemos traer a colación esta prueba de imprenta es porque fue presentada como prueba pericial durante el pleito que dirimieron en 1609 Juan de Ibero y Carlos de Labayen. Somos realmente afortunados de contar con este rico testimonio gracias a que Ibero denunció al impresor pamplonés porque según él Labayen «recibió los treinta ducados con más siete resmas de papel» pero "no ha proseguido ni hecho caso nenguna», por lo que «no sería raçon que se quedase con la dicha cantidad $»^{2}$. Sin embargo, el abogado de Carlos de Labayen alegaba en su favor que "los dichos treinta ducados fue con expresa condición y presupuesto que por cuanto el dicho Labayen no tenía letra ni caracteres cualesquiera y deseaba el dicho Licenciado para la impresión de su libro el dicho Labayen hubiese de traer mucha forma de letras compradas en Çaragoça» ${ }^{3}$. Añadiendo, a su vez, que «mi parte está presta de cumplir de su parte lo concertado acerca de la dicha impresión y no ha faltado ni falta por él y en caso que el dicho Licenciado Ibero no lo quiera ha de pagarle todos los dichos daños y menoscabos» ${ }^{4}$.

Vemos, por tanto, como la documentación judicial se erige en este caso en la fuente documental básica para acometer nuestra investigación. De este modo, dados los objetivos del presente artículo hemos profundizado hoja por hoja en las confesiones de cada testigo, en las declaraciones de los acusados, en las pruebas presentadas y en los argumentos dados por la defensa y el fiscal. Todo ello para tratar de buscar indicios que nos ayuden a reconstruir la intrahistoria del proceso editorial durante el Siglo de Oro. A su vez, gracias al ejemplo que traemos a colación podremos no sólo apreciar la historia editorial de la obra Novus et Analyticus Commentarius, sino también el papel que ostentaba el autor cuando actuaba como editor o la actitud del impresor cuando se comprometía con un encargo editorial. No obstante, este pleito también nos muestra una vez más las desavenencias que solían ocasionarse cuando una de las partes incumplía lo acordado a la hora de publicar un texto. Por un lado tendríamos las quejas de los autores por la mala calidad de los trabajos o la tardanza en editar sus obras, mientras que, por el otro, aparecerían los impresores agraviados porque el autor-editor no cumplía con los pagos estipulados o con la entrega del papel preciso para sacar la edición.

Esto hace que, desde nuestro punto de vista, los procesos judiciales se erijan en una fuente de un extraordinario valor para escudriñar valores de suma relevancia para la comprensión de cualquier sociedad del Antiguo Régimen. En

2. AGN, Tribunales Reales. Procesos, núm. 330464, fol. 3 r.

3. AGN, Tribunales Reales. Procesos, núm. 330464, fol. 4r.

4. AGN, Tribunales Reales. Procesos, núm. 330464, fol. 4v. 
este caso, por ejemplo, la documentación procesal nos aporta un rico torrente informativo a través de los interrogatorios que se llevaron a cabo durante el juicio, con lo que podemos conocer datos que nos remiten a circunstancias, costumbres o acontecimientos de vital interés para ir reconstruyendo el devenir del libro en la Navarra de los siglos modernos.

Lo cierto es que la imprenta tuvo un temprano despertar en tierras navarras a finales del siglo XV, aunque después, tras la conquista castellana de principios del XVI, experimentó un proceso de letargo hasta mediados de aquella centuria. Bien es cierto que fue durante el siglo XVII cuando la industria editorial se asentó en el reino. De esta manera, a una comprensión satisfactoria de las artes gráficas en el Siglo de Oro nos ayuda el estudio de las causas judiciales que se entablaron ante los Tribunales Reales. Sin duda, son varias las ventajas que encierra el uso de este tipo de fuente, entre las que podemos destacar:

- Permite conocer los valores sociales y morales desplegados en unas formas de pensar, sentir y actuar que son expresadas y justificadas en las alegaciones presentadas ante los jueces, tanto para condenar un comportamiento delictivo por parte de los demandantes, como para excusarlo por parte de los acusados.

- Las penas impuestas a los reos durante el desarrollo de los pleitos entablados favorece que se tenga constancia de la consideración social de los delitos y hasta qué punto los jueces siguieron los dictados de la legislación penal del reino.

- Ayuda a vislumbrar de forma satisfactoria quiénes se encontraron detrás de la producción y venta de libros en Navarra, analizando tanto a los impresores como a los libreros.

- Posibilita un mejor conocimiento de la figura del autor cuando actuaba como editor, pudiéndose apreciar su protagonismo en el proceso de edición.

- Favorece una comprensión óptima de los motivos reales que ocasionaron las denuncias que tuvieron lugar ante los Tribunales Reales de Navarra en relación con la industria editorial.

- Las declaraciones de los testigos presentados en las distintas causas judiciales nos ofrecen una rica y detallada información sobre la concepción que éstos tenían de ciertas actuaciones delictivas.

Por tanto, las fuentes judiciales se muestran como un medio de un extraordinario valor para poder adentrarnos en la microhistoria que nos pone de manifiesto cada uno de los casos que fueron juzgados. No obstante, cada pleito debe ser puesto en relación con la totalidad histórica, contextualizando y analizando cada suceso dentro de un todo más amplio y complejo.

Junto a los procesos judiciales otra de las fuentes más relevantes para conocer el mundo editorial durante el Antiguo Régimen es la documentación notarial. Este género documental nos permite conocer aspectos muy sugerentes, pues no solo se trata de conocer los libros que fueron impresos, sino además las actividades comerciales de impresores y libreros. En consecuencia, debemos 
destacar que los protocolos notariales, si bien acogen una riqueza documental muy excelsa, no es menos cierto que ayudan al investigador -como sugieren Pedraza $^{5}$, Rodríguez de Gracia ${ }^{6}$, Rojo Vega - a adentrarse en una serie de aspectos que le facilitarán la reconstrucción de un fenómeno tan complejo como el de la producción editorial. El rastro dejado por este tipo de documentación que se encuentra en muchos archivos nos ayuda a estudiar multitud de variables en torno al mundo de la imprenta en determinados espacios geográficos, lo que, a su vez, nos permite extrapolar situaciones concretas a las evidencias registradas en otros enclaves de la Monarquía Hispánica. Son muy variadas las ventajas que nos puede reportar el uso de documentación notarial, aunque para nuestro objeto de estudio serían las siguientes:

- Testimonian actos entre distintas partes que nos reportan datos de vital interés para conocer diversas prácticas del mundo editorial, caso de los contratos de edición, la compra de materiales de impresión o los mandamientos de pago.

- Aproximan al investigador a las relaciones familiares, sociales y mercantiles que mantuvieron los impresores y libreros del reino de Navarra con los profesionales asentados en territorios vecinos, caso de Zaragoza en la Corona de Aragón o de Bayona y Burdeos en Francia.

- Recogen la información necesaria para que podamos atisbar algunas de las pautas comerciales más usuales de la época.

- Permiten reconstruir de forma fehaciente las modas editoriales a través de los contratos de impresión, con lo que podemos ser conscientes no sólo de los gustos en la lectura, sino además del funcionamiento del mercado.

- Arrojan ricos testimonios sobre la percepción que tuvieron del negocio editorial los principales protagonistas ante la proliferación de libros impresos, como lo fueron impresores, libreros y autores de aquellas obras.

Pese a ello, debemos ser conscientes de que el recurso a este tipo de fuentes nos aporta una visión sucinta de lo realmente acontecido en un territorio concreto. Además, no podemos afirmar que se haya conservado toda aquella documentación que fue producida por los notarios, lo que introduce un claro factor de inestabilidad. Sin embargo, qué duda cabe que el uso de protocolos notariales nos acerca al mercado del libro en distintas facetas, caso del conocimiento de las modas editoriales, las prácticas profesionales o las relaciones mercantiles, aunque por encima de todo cabe destacar la aproximación a la

5. Manuel José Pedraza Gracia, El libro español del Renacimiento. La vida del libro en las fuentes documentales contemporáneas, Madrid, Arco Libros, 2008, p. 81.

6. Hilario Rodríguez de Gracia, "Contratos de impresión suscritos por Juan de Mariana, Alonso de Villegas y Francisco de Pisa», Hispania sacra, 55, 111, 2003, p. 79.

7. Anastasio Rojo Vega, "Comercio e industria del libro en el noroeste peninsular: Siglo XVI», en P. M. Cátedra y M. L. López-Vidriero, El libro antiguo español, Salamanca, Universidad de Salamanca, 1992, p. 425. 
figura de todos aquellos personajes que se vieron envueltos en el fenómeno editorial durante aquellas centurias. Bien es cierto que, como asevera Pedraza ${ }^{8}$, pese a su enorme valor se hace imprescindible recurrir a otras fuentes que nos permitan una comprensión más certera del fenómeno editorial durante la Edad Moderna, puesto que se alcanzan conclusiones mucho más completas si se entrecruzan y fusionan distintos tipos documentales en investigaciones de esta naturaleza.

Dentro de la gama de escrituras que podemos encontrarnos al bucear en los protocolos notariales de cualquier archivo debemos resaltar que uno de los tipos documentales que más y mejor información aporta sobre la historia de la imprenta son los contratos de edición?. En ellos los intervinientes actuaban como los únicos protagonistas de la producción de un determinado producto editorial gracias a las condiciones que se estipulaban entre las cláusulas de dichas capitulaciones de impresión. Pero lo más relevante, como advierten Pedraza $^{10}$ y Lucía Megías ${ }^{11}$, es que en este tipo documental no sólo se recogían interesantes datos económicos, sino que también se esbozaban los caracteres técnicos de la edición contratada.

En el caso que nos ocupa debemos resaltar que no se terminó de hacer la escritura final, aunque por la declaración del notario del acto en el que se hizo el borrador se puede llegar a reconstruir alguno de sus aspectos materiales. Pedro de Burlada, escribano real, declaraba que en diciembre de 1607 fue llamado por Juan de Ibero a su convento porque «había de hacer una escritura de obligación y convenios» sobre que Labayen «le había de imprimir un libro». Estando así presentes Ibero y Labayen «conforme a una minuta que se la hizo escribir ordenándola el propio señor Ibero, que está escripta en veinte y tres renglones y medio». No obstante, según Burlada "queriendo començar hacer la dicha escritura conforme la dicha minuta llegaron a la saçon el padre Olivares y otros frayles, sus compañeros de la orden de Santo Domingo de esta ciudad, a cuya causa cesó el hacerse la dicha escritura», a lo que Ibero «le dijo a este testigo que se fuese a su casa y levantase la dicha escritura de la mesma forma y manera y en las condiciones contenidas en la dicha minuta» $y$ «acabada volviese para que la firmase» ${ }^{12}$. Bien es cierto que no tenemos noticia de que esto llegase a producirse, pues no es solo que no se conserve en los protocolos notariales

8. Manuel José Pedraza Gracia, op. cit., 2008, p. 103.

9. Sobre esta cuestión puede consultarse el trabajo donde se abordan los contratos editoriales suscritos en Pamplona durante el siglo XVII. Véase Javier Ruiz Astiz, «El editor y sus exigencias: convenios de impresión en la Pamplona del siglo XVII», en M. J. Pedraza Gracia (dir.), Doce siglos de materialidad del libro: estudios sobre manuscritos e impresos entre los siglos VIII y XIX, Zaragoza, Prensas de la Universidad de Zaragoza, 2017, pp. 401-420.

10. Manuel José Pedraza Gracia, «Las muestras en las capitulaciones para la impresión de libros: análisis de dos muestras del siglo XVI», Pliegos de bibliofilia, 13, 2001, p. 33.

11. José Manuel Lucía Megías, Aqui se imprimen libros. La imprenta en la época del Quijote, Madrid, Ollero y Ramos, 2005, p. 108.

12. AGN, Tribunales Reales. Procesos, núm. 330464, fol. 59r. 
ningún testimonio de esta escritura, sino que, además, de haber existido se hubiera presentado como prueba durante el transcurso del pleito.

En suma, lo que nos permiten la multitud de fuentes documentales que se conservan diseminadas en todo tipo de archivos es poder reconstruir el pasado de la forma más eficiente posible. Gracias a ellas y a los investigadores que las rescatan la Historia del Libro consigue -y conseguirá en un futuro- acabar con muchos de los silencios que nos impedían conocer diferentes aspectos relacionados con la edición de textos en el Siglo de Oro. Esa historia interna a la que hacía referencia el profesor Infantes ${ }^{13}$ se erige, hoy más que nunca, en la clave maestra para desentrańar la intrahistoria de buena parte de las obras que se conservan en nuestras bibliotecas.

\section{El proceso de edición de NovUs et Analyticus Commentarius}

Como hemos visto, muchos y variados son los testimonios que se conservan en todo tipo de fuentes documentales, por lo que a la hora de abordar el estudio de la edición de un determinado texto es habitual encontrarse con datos que nos muestran la estrecha relación que mantuvieron autores e impresores. Si bien es cierto que, como sugería Infantes ${ }^{14}$, el análisis del proceso editorial de cualquier obra nos suele ofrecer una información mucho más amplia, caso de sus características técnicas, su tirada, el precio o las redes de distribución.

En este caso, como en otros muchos, el proceso de edición comenzó con la intención de transformar un original manuscrito de Juan de Ibero en una obra impresa. Como era habitual en el Siglo de Oro, fue el editor quien asumió los costes derivados de la producción y publicación de dicho texto. Qué duda cabe que este personaje, y más teniendo en cuenta que actuó como tal el propio autor, se erigió en una figura de una enorme relevancia desde un inicio. Suyas fueron las decisiones que marcarían el proceso productivo desde el principio hasta el final, aunque es cierto que más que decisiones podríamos hablar de exigencias que condicionaron el trabajo que debía desempeñar el impresor. Consideramos que fueron más requerimientos hechos por el autor-editor porque él a la hora de concertar con Carlos de Labayen la impresión de su obra indicó algunos condicionantes que eran ineludibles desde su punto de vista. A su vez, no debemos olvidar que Ibero fue quien decidió elegir al impresor que iba a llevar a cabo la edición, pues en 1607 tenemos noticias de más tipógrafos asentados en Pamplona, caso de Matías Mares y Nicolás de Asiáin.

Es habitual encontrarse en esta época a muchos autores concertando con el impresor la impresión de su obra. En estos casos el autor contrataba los servicios de un taller de imprenta para llevar a cabo la producción de los ejemplares acordados de su texto. Por tanto, era el autor-editor quien se hacía

13. Víctor Infantes, «La muestra de impresión: un testimonio inédito de la estrategia editorial del Siglo de Oro", en A. Cayuela, Edición y literatura en España (siglos XVI y XVII), Zaragoza, Prensas Universitarias, 2012, p. 137.

14. Ibid., pp. 138-139. 
cargo de todo el riesgo económico, aunque como vemos en nuestro pleito las desavenencias monetarias con los impresores fueron habitualmente fuente de conflictos y disputas en los tribunales ${ }^{15}$. Si bien una de las características esenciales de este tipo de ediciones, como acertadamente señalan Lucía Megías ${ }^{16}$ y Pedraza ${ }^{17}$, es que los autores al ejercer también como editores fueron extremadamente celosos a la hora de supervisar todo el trabajo: contenido, composición y erratas.

Entre sus cometidos su atención se centraba, primero, en la calidad técnica de la edición, por lo que incluso solían exigir la adquisición de una letrería menos gastada para que el texto tuviese una imagen más pulcra y la edición quedase mejor acabada. Es Diego de la Torre, impresor afincado en Estella, quien nos dice que "habiendo principiado a componer de la materia del libro no se ha contento el dicho Licenciado Ibero de la letra que el dicho Labayen tenía» y «se concertaron en que el dicho Labayen fuese a Çaragoça a traer la letra ${ }^{18}$. Asimismo, el propio Labayen indicaba que «las letras que compró y traxo" para "esta ocasión le costaron cincuenta ducados y les pagó a Felipe y Joan de Bonilla, libreros, vecinos de la dicha ciudad de Çaragoça» ${ }^{19}$. Por tanto, una de las primeras exigencias del autor-editor fue que el impresor adquiriese una letra más cuidada para que el producto tuviese una mayor calidad.

Junto a ese criterio tanto personal como mercantilista, no debemos olvidar que el autor corría con todos los gastos y debía amortizar su inversión con la posterior venta de ejemplares, por lo que no hay que menospreciar la importancia que le daban a la contratación de buenos profesionales para que la obra tuviese una técnica más depurada y la publicación fuese atractiva. Esta fue la segunda exigencia de Juan de Ibero, ya que según Labayen «hizo venir de Çaragoza con expressa orden del dicho Licenciado Ibero dos oficiales de imprimir y los tuvo un mes de tiempo a su costa $»^{20}$. Dos oficiales que como señala Diego de la Torre, «el uno de la caxa componedor y el otro tirador de la prensa, llamados Domingo Hernández y Pedro de Berjes» ${ }^{21}$. Pero hubo más exigencias, pues conocemos según Fray Martín de Bertiz, mercedario, que estando imprimiendo un libro «intitulado las postrimerías» por orden de su convento «es notorio que andando así le dijo el dicho Carlos de Labayen como el dicho Licenciado Ibero le había mandado dejar todas las obras que tenía y había de comenzarse hacer primer libro suyo» ${ }^{22}$. Como vemos, el requerimiento

15. Véase Javier Ruiz Astiz, «Litigantes ante los Tribunales Reales de Navarra: impresores y libreros durante los siglos XVI y XVII", Titivillus. Revista Internacional sobre Libro Antiguo, 1, 2015, pp. 325-339.

16. José Manuel Lucía Megías, «El texto dentro y fuera de la imprenta: cara y cruz de la edición», en J. M. Lucía Megías, Imprenta, libros y lectura en la España del Quijote, Madrid, Ollero y Ramos, 2006, p. 308.

17. Manuel José Pedraza Gracia, op. cit., 2008, p. 135.

18. AGN, Tribunales Reales. Procesos, núm. 330464, fol. 20r.

19. AGN, Tribunales Reales. Procesos, núm. 330464, fol. $4 \mathrm{r}$.

20. AGN, Tribunales Reales. Procesos, núm. 330464, fol. 4r.

21. AGN, Tribunales Reales. Procesos, núm. 330464, fol. 20v.

22. AGN, Tribunales Reales. Procesos, núm. 330464, fol. 58r. 
del autor del texto implicó la dedicación en exclusiva de todos los operarios del taller en torno a su libro.

Por último, dentro de sus exigencias solemos encontrarnos con el hecho de examinar cada cierto tiempo o según el número de pliegos lo que se conocen como pruebas de imprenta. Una práctica que también se siguió en nuestro caso, tal y como detalla Diego de la Torre, pues indicaba que él «como oficial del dicho Labayen componía en su casa y empeço el libro» después de traer las nuevas letras desde Zaragoza, con lo que «se principió a componer los pliegos y pruebas que están presentados en proceso» ${ }^{23}$. Durante la fabricación tenían cabida posibles modificaciones en el texto que permitían presentar un trabajo final más eficiente y acorde con las exigencias del editor que costeaba la edición. En consecuencia, cuando la figura del autor era coincidente con la del editor es habitual encontrarlos, como exponen Pedraza ${ }^{24}$ y Ruiz Astiz ${ }^{25}$, interviniendo en distintos momentos siempre que fuese posible para corregir posibles erratas o imperfecciones en las pruebas que le eran mostradas. Por tanto, el autoreditor aparece muchas veces aprobando o rechazando los pliegos impresos que le remitían los impresores diaria o semanalmente.

Sentadas estas premisas comprobamos que una vez entregado el original manuscrito por el autor comenzaba en la imprenta un proceso manual que debía finalizar con la impresión de los ejemplares acordados en los contratos suscritos. Se trataba de una etapa englobada por distintas fases en las que los componedores y cajistas ostentaban un papel primordial, pues como consecuencia de sus posibles descuidos, las malas interpretaciones o la falta de tipos en el taller, un texto podía experimentar leves o acusadas transformaciones. De ahí la importancia de la corrección de pruebas de imprenta durante el Siglo de Oro.

\section{LA PRUEBA DE IMPRENTA COMO TESTIMONIO MATERIAL}

Desde la aparición de la imprenta, habitualmente en cualquier taller, antes de proceder a la impresión definitiva de un texto se componía una primera estampación que actuaba a modo de prueba. Una práctica que hundía sus raíces en la corrección de manuscritos que tan usual había sido en épocas anteriores. Pero, ¿cómo se definía el término prueba? Según el Tesoro de Covarrubias "prueva o prova» sería «el primer pliego de la imprenta, que se corrige ${ }^{26}$. Una acepción que un siglo después se completaría en el Diccionario de Autoridades, ya que en una de las acepciones de "prueba» se decía: «llaman los impressores la primera plana que tiran en papel ordinario, para corregir y apuntar en ella las erratas que tiene, de suerte que se puedan emendar antes de tirarse» ${ }^{27}$. De este modo, el propósito de la confección de aquellas pruebas de

23. AGN, Tribunales Reales. Procesos, núm. 330464, fol. 20v.

24. Manuel José Pedraza Gracia, op. cit., 2008, p. 115.

25. Javier Ruiz Astiz, op. cit., 2017, pp. 412-413.

26. Tesoro de la lengua castellana, Madrid, Turner, 1984, p. 885.

27. Diccionario de Autoridades, Madrid, Gredos, 1976, t. III (O-Z), p. 418. 
imprenta no era otro que conseguir un texto lo más pulcro posible, evitándose así cualquier tipo de errata que pudiera surgir durante la transposición del manuscrito al impreso. Tal era su cometido que una vez que los posibles errores habían sido advertidos y después solventados, estas pruebas dejaban de ser útiles y se desechaban, de ahí que no se hayan conservado muchas.

Debido a esto, cuando localizamos una no podemos sino felicitarnos porque contamos con un testimonio trascendental para reconstruir el proceso editorial de una determinada obra. Además, como sugiere Garza ${ }^{28}$, su provisionalidad hace que las pruebas de imprenta adquieran unos caracteres únicos porque la impresión definitiva podía distar mucho de esa primera impresión. En nuestro caso, a su vez, cobra especial relevancia la prueba localizada porque finalmente la obra de Juan de Ibero no fue publicada, ya que el trabajo concluyó debido a una larga enfermedad que aquejó al autor durante casi dos años. Sin embargo, han llegado hasta nuestros días una serie de pliegos y hojas sueltas que constituyen la evidencia material de que aquella edición se planeó y comenzó, pues lo corrobora la prueba de imprenta conservada en el pleito que se dirimió en 1609 entre Juan de Ibero y Carlos de Labayen.

Por lo general se tiende a destacar el papel del componedor y de los cajistas en cualquier edición, pese a que el corrector de pruebas -cuando existía- tenía una gran relevancia y su intervención resultaba clave. No obstante, ¿qué papel ostentaba el autor dentro de la corrección de pruebas? Todos tendemos a pensar en una figura profesional cuando hablamos del corrector, pero no cabe duda de que muchas veces cuando se concertaba la impresión de una obra se acordaba sacar las conocidas como pruebas de imprenta para que fuese el propio autor-editor el que las corrigiese detenidamente para dotar a su texto de mayor excelencia ${ }^{29}$. Habitualmente podían darse dos situaciones; bien que los autores pasasen por el taller para hacer allí posibles correcciones o, lo más frecuente, que el impresor le llevase a su casa o a su lugar de residencia las pruebas para que las pudiese examinar con un mayor detenimiento.

Esto último es lo que sucedió en el caso que estamos estudiando, puesto que las mencionadas pruebas fueron remitidas al convento de Santo Domingo donde residía Juan de Ibero. Nosotros no podemos averiguar el papel que debía desempeñar el autor en la corrección de pruebas a través del concierto suscrito para la edición de su obra, pero sí podemos constatarlo a través de las declaraciones recogidas en el pleito y la demanda interpuesta por el impresor. De este modo, Labayen alegaba en su defensa que "començada a hacer al tiempo que cayó enfermo el dicho Licenciado Ibero y estaban ya impresos para este tiempo seis pliegos como se ve por el original que presento con las

28. Sonia Garza Merino, «Imprenta manual y pruebas de imprenta», en A. Cayuela, Edición y literatura en España (siglos XVI y XVII), Zaragoza, Prensas Universitarias, 2012, p. 114.

29. Véanse los trabajos de Trevor J. Dadson, «La corrección de prueba (y un libro de poesía)», en F. Rico, Imprenta y critica textual en el Siglo de Oro, Valladolid, Universidad de Valladolid, 2001, p. 116; Manuel José Pedraza Gracia, op. cit., 2008, p. 269; Pablo Andrés Escapa, Elena Delgado, Arantxa Domingo y José Luis Rodríguez, «El original de imprenta», en F. Rico, Imprenta y crítica textual en el Siglo de Oro, Valladolid, Universidad de Valladolid, 2001, p. 45. 
enmiendas de mano del dicho Licenciado ${ }^{30}$. Junto a este testimonio es Diego de la Torre, oficial en el taller de Labayen, quien señaló que la impresión de pruebas debía de estar acordada previamente entre autor e impresor, pues según él «se principió a componer los pliegos y pruebas que están presentados en proceso como se acostumbra»" ${ }^{31}$.

Como se evidencia, el testimonio que presentamos en este artículo constata que durante la imprenta manual existió un claro interés por sacar el libro exento de erratas, por lo que el papel del autor-editor en la corrección de pruebas resultaba elemental. Una práctica que incluso antes de procederse a la composición de la obra ya se solía acordar porque era lo más habitual en aquella época. Bien es cierto que no es lo mismo disponer de la prueba de imprenta físicamente en nuestras manos que ser conscientes de que debió de existir en un momento preciso. En consecuencia, suscribo la acertada visión de Dadson $^{32}$, ya que gracias a estudios de esta naturaleza no sólo somos capaces de conocer el papel jugado por muchos autores en la corrección de pruebas, sino que al mismo tiempo podemos comprender de forma satisfactoria cómo se editaba un libro en el Siglo de Oro.

\section{ANÁLISIS DE LAS CORRECCIONES HECHAS POR EL AUTOR-EDITOR}

La prueba que se presenta demuestra que Juan de Ibero era un personaje sino experimentado, sí conocedor de la corrección de textos porque se aprecian toda una serie de marcas y símbolos que servían para señalar los errores y las partes que se debían bien suprimir o añadir al texto. Pero, ¿quién era este personaje? Conocemos poco de él, principalmente lo datos que nos ofrece la portada del libro y alguna información que entresacamos del pleito. Por lo que parece estudió en el Colegio de Santiago Zebedeo de Salamanca y fue profesor de Derecho Canónico, siendo miembro después del Consejo Real de Navarra. Además, podría ser miembro del linaje de los Ibero $^{33}$ por la referencia al solar de Eraso y Oteiza. Esta información nos la aporta la portada de la obra, pero además durante el proceso judicial se nos dan distintas pistas que nos llevan a pensar que fue dominico. Poco más sabemos de él por el momento, aunque esperamos poder desentrañar más aspectos de su biografía en un futuro.

30. AGN, Tribunales Reales. Procesos, núm. 330464, fol. 4v.

31. AGN, Tribunales Reales. Procesos, núm. 330464, fol. 21 r.

32. Trevor J. Dadson, op. cit., 2001, p. 119.

33. Tenemos noticia de la existencia de una familia muy relevante en la vida navarra de finales del XVI y principios del XVII encarnada en la figura de Juan de Ibero y su hermano, Juan Francisco de Ibero. Los datos recabados hasta ahora no nos permiten afirmar que el autor del texto Novus et Analyticus Commentarius fuese uno de ellos porque dice llamarse Juan de Ibero Ciriza, aunque el hecho de que se intitule "Villae de Erasso et Oteyza Domino» hace pensar que podría ser alguien emparentado con ellos, aunque no lo podemos afirmar con certeza. Para profundizar sobre el linaje de los Ibero véase María Dolores Martínez Arce, «Nobleza de Navarra: Organización familiar y expectativas de futuro», Vasconia, 28, 1999, pp. 178-180. 
No debe sorprendernos el hecho de que este personaje contase con cierta destreza a la hora de corregir textos, pues como indica André ${ }^{34}$ los autores comenzaron a corregir las pruebas de imprenta de sus propios textos, algo que se observa a la perfección en los textos con enmiendas que devolvió Ibero a Carlos de Labayen. En ellos aparecen toda una serie de signos que tenían un determinado significado:

- Separar palabras que se han juntado por error (trazo vertical ( | ) indicando el punto de separación).

- Reducir un espacio en blanco innecesario (trazo diagonal o vertical ( / o $\mid$ ), dependiendo del caso).

- Delimitar el espacio uniendo dos palabras que se han escrito separadas y deben ir juntas formando un solo vocablo (trazo horizontal bajo (u) en forma de «u» pequeña o una barra ( $\_$) baja).

- Añadir un carácter tipográfico (se emplea una «V» invertida $(\wedge)$ que se dibuja en el lugar donde debía de añadirse un elemento tipográfico: letra o signo de puntuación).

- Localizar errores y remplazar letras (raya vertical (| ) o una pequeńa tachadura $(l)$ hecha sobre una o dos letras indicando que han de corregirse y la enmienda correspondiente se anota al margen o encima de la palabra que estaba mal escrita).

- Remplazar una o varias palabras por otras para cambiar parte de una frase (tachadura sobre la palabra o palabras a sustituir y las nuevas expresiones se advierten bien en el margen o encima de las palabras tachadas).

Dicho esto, conviene centrarse ahora en las correcciones que hizo Ibero sobre la prueba de imprenta que le presentó Carlos de Labayen. Primero tendríamos que señalar que aparece la portada (fol. Gr), donde aparte de fijarnos en algunos datos que nos ayudan a ubicar al autor, o al menos a conocer algo más de él, podemos apreciar un único elemento de corrección introducido por el autor, ya que en la cuarta línea del título aparece una barra diagonal para eliminar un espacio («quae sub modo.I Vbi conuentionalis successio...»).

Tras la portada aparece una dedicatoria a Felipe III (fols. 7r y 8v). En la primera nos encontramos con algunas erratas, aunque principalmente se localizan errores de distribución de los espacios en esta composición porque abundan las llamadas a través de rayas verticales ( | ) para señalar los espacios o separaciones entre palabras que se debían introducir. Son varios los ejemplos que podrían ser señalados («num|quos», «naufragij|tabulam»o "donum|illud»). Junto a esto, cabe destacar que hay algunos casos de llamadas para unir palabras que se han separado y pueden llevar a error con el símbolo ( $)$, indicando de este modo la unión de dos partes. Entre los casos advertidos tendríamos dos: «suppedituaretaquam» o "desulibatam». Por otro lado, para que se modifique una letra Ibero utilizó el símbolo (l), caso de «mancu» que lo reemplaza por

34. Jacques André, «Petite histoire des signes de correction typographique», Cabiers GUTenberg, 31, 1998, p. 52. 


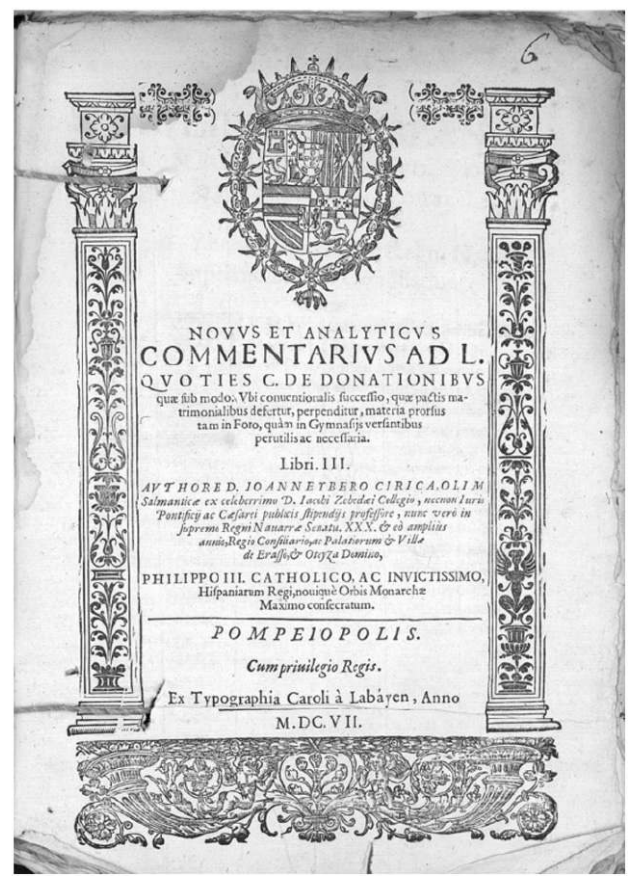

Imagen 1. - Portada

(AGN, Corte Mayor, proceso n. 330464, fol. 6r)

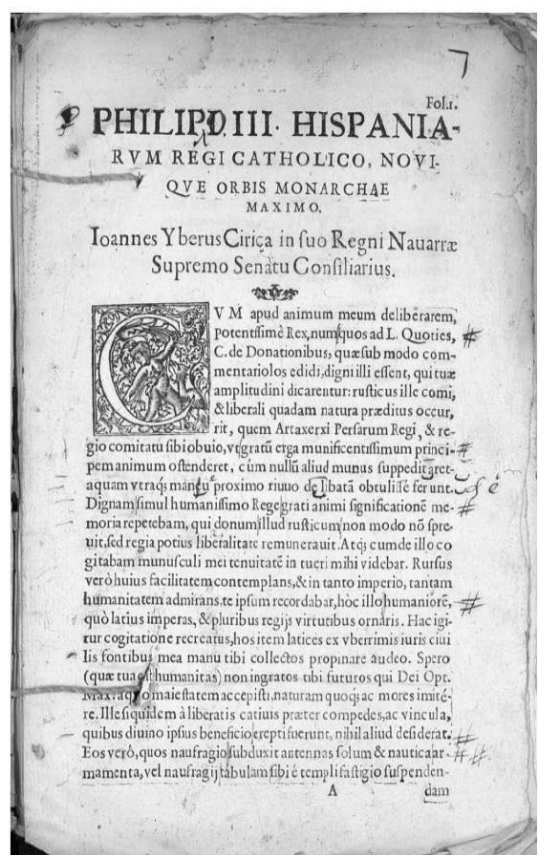

Imagen 2. - Dedicatoria a Felipe III (AGN, Corte Mayor, proceso n. 330464, fol. $7 \mathrm{r}$ )

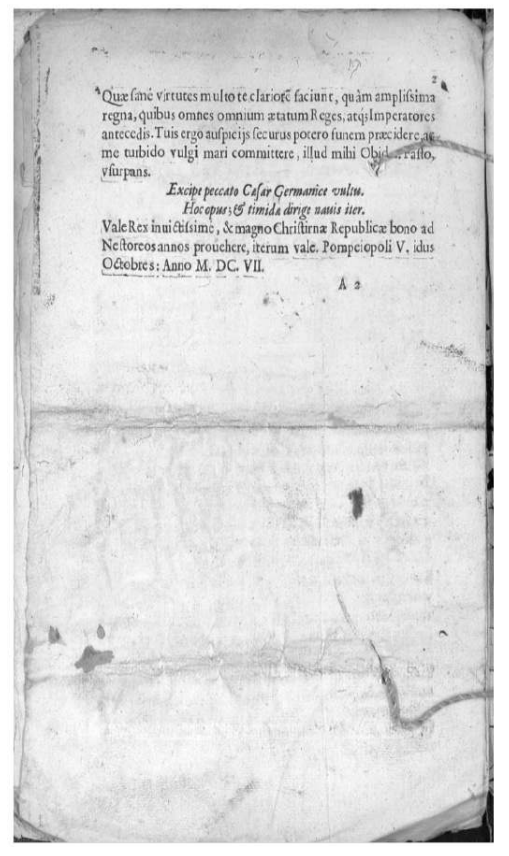

Imagen 3. - Dedicatoria a Felipe III (AGN, Corte Mayor, proceso n. 330464, fol. $8 \mathrm{v}$ ) 
«maneu». Asimismo, a la hora de añadir alguna letra que había sido olvidada recurrió al símbolo $(\wedge)$, como sucede en el nombre de "Philipo III", al que le faltaba una "p» (Philippo III). No obstante, por último, otro recurso identificado es escribir la letra que sustituye a la que se ha empleado mal por encima, como cuando ańade la «o» por la «i» en el nombre del monarca, ya que había impreso «Philipi III». Todo esto en lo que se refiere al folio 7r, pues la parte final de la dedicatoria al monarca que se encuentra en el folio $8 \mathrm{v}$ no tiene ninguna corrección manuscrita hecha por el autor.

Después nos encontramos con una Invocatio en el folio 9r bajo el enunciado: Divininuminis, divorumque tutelarium invocatio ab eodem autore. En este caso nos volvemos a encontrar con las barras verticales que indican la necesaria separación de palabras ( | ), como por ejemplo sucede en «cuius|cope». A su vez, llama la atención la eliminación de un paréntesis que debía de estar mal colocado ( / ) al principio, antes de «ingressuro», y además añadió el símbolo «\&» tanto en el margen como en el texto para conformar la expresión: «studium \& ingressuro». Por otro lado, vemos que recurrió también al símbolo ( / ) para quitar una letra en el caso de "palestram" por "palaestram», y ya en la parte de abajo nos avisa de que ha añadido una «n» para conformar la palabra «cliens» y sustituirla por la letra que erróneamente se había dispuesto en el taller de imprenta.

Ya en el folio 10v en el Epigramma ad lectorem no se advierte ninguna corrección hecha por Juan de Ibero. Tras ello en el folio 11r que se intitula Epoeneticon in laudem autoris sí que se aprecian distintos tipos de correcciones manuscritas para que el impresor las tuviese en cuenta después en su taller. De este modo, entre las correcciones tendríamos nuevamente la separación de palabras con el símbolo $(\mid)$, caso de «intus|opes» o «dic|itun». Del mismo modo corrigió expresiones que debían de estar mal compuestas escribiendo encima la letra correcta, como sucede al principio cuando pone una "A» para que se lea "AQVODAM", ya que se aprecia que debajo de la primera letra había una «L». A su vez, con el símbolo ( $\mid$ ) indicaba en dos ocasiones también letras que debían ser añadidas o que sustituyesen a otra, advirtiéndolo al mismo tiempo en el margen, así se debe añadir «s» a la palabra «e|flunijs» y sustituir lo que parece una «s» por una «o» para conforma la palabra «cano» en vez de «cans».

Después del Epoeneticon tendríamos en el folio $12 \mathrm{v}$ la Protestatio autoris. A simple vista en este caso hay más errores, además de ser los mismos de diversa naturaleza. Como siempre para separar palabras y dejar espacio empleaba el símbolo ( | ), como en el caso "proprijs|expensis». Además sigue indicando con una barra baja ( $~()$ la unión de dos partes de una palabra que aparecen con un espacio innecesario, como en el caso de «philosophy_ae». Modificó, a su vez, el paréntesis porque lo amplía para acoger dos palabras más e indica en dónde debía de colocarse el nuevo. Dicho esto, lo que se observa en abundancia son numerosos errores que son corregidos por el autor tanto indicando en los márgenes con llamadas lo que se debe añadir para corregir errores en palabras o directamente tachando con una barra ( / ) la letra o letras, escribiendo arriba 


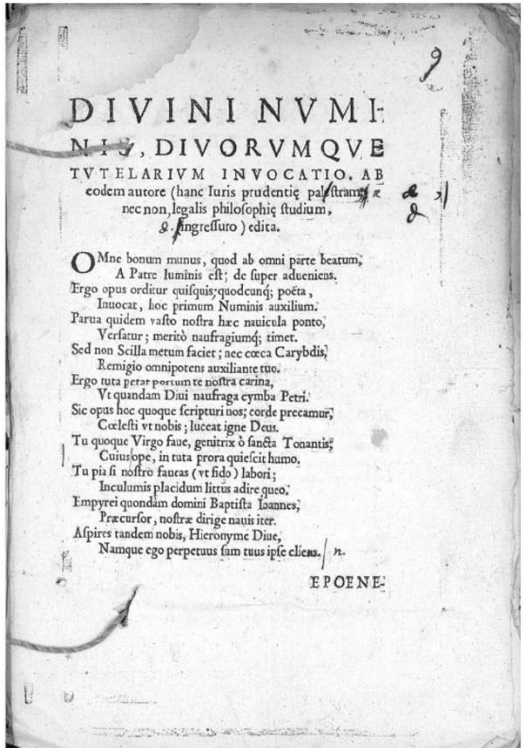

Imagen 4. - Invocatio (AGN, Corte Mayor, proceso n. 330464, fol. 9r)

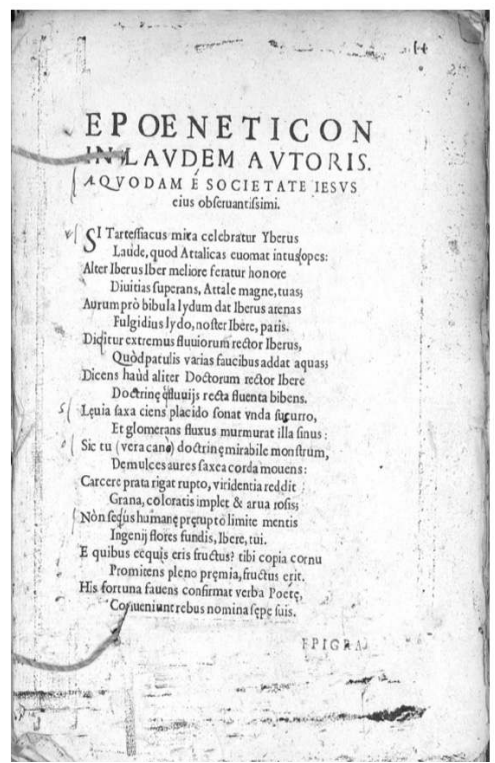

Imagen 6. - Epoeneticon in laudem autoris (AGN, Corte Mayor, proceso n. 330464, fol. 11r)

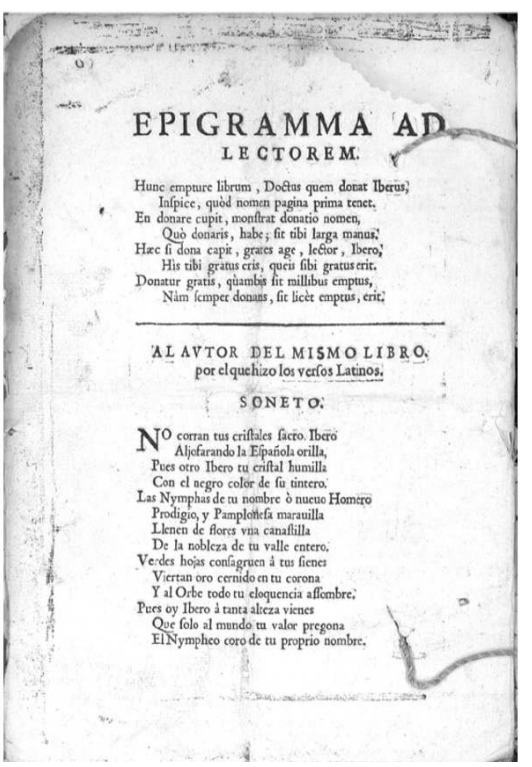

Imagen 5. - Epigramma ad lectorem (AGN, Corte Mayor, proceso n. 330464, fol. 10v)

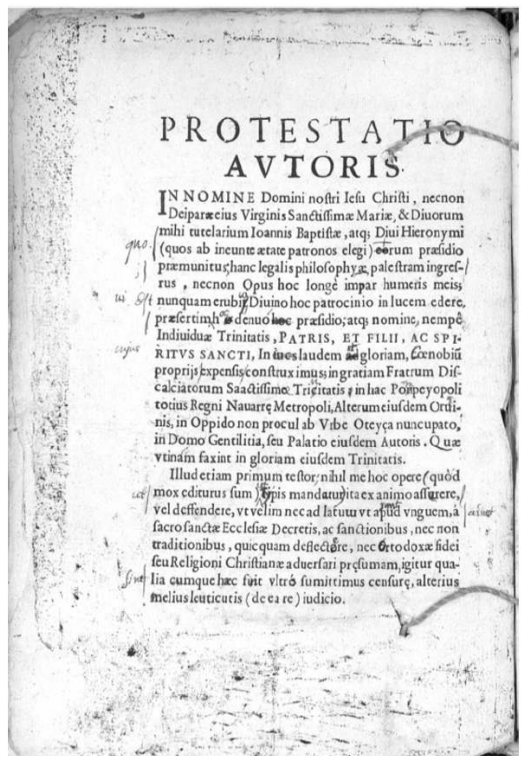

Imagen 7. - Protestatio autoris

(AGN, Corte Mayor, proceso n. 330464, fol. 12v) 
lo que debe añadirse para que esté bien expresado en latín. Entre estos casos podríamos destacar, por ejemplo, "quorum» por «corum», «cuius» por «iucs» o «fint» por «fuit», aunque hay otros casos de sustitución de una única letra, como cuando en "Tricitatis» indica que la «c» debe ser sustituida por una «n" para que sea "Trinitatis», así como en el caso de "Ponpeyopolitotius» en que la «n» debe ser una «m» para que sea «Pompeyopolitotius», o también el caso de «deflectore» que debe ser sustituido por «deflectere».

Llegamos posteriormente al Summaria que está repartido entre los folios $13 \mathrm{r}$ y $14 \mathrm{v}$ de dicho pliego. En el primer folio se aprecian bastantes errores gramaticales que el autor trató de corregir detenidamente. Primero sigue anotando con el símbolo ( | ) los espacios que deben añadirse para que no se junten dos palabras, caso de «elucidationem|non». Al margen de esto, el resto son correcciones ortográficas de distinto calado. Entre ellas nos encontramos, primeramente, con la eliminación de alguna letra tachándola porque sobra, así «traditum» se debe sustituir por «traditum». Junto a ello, se advierten equivocaciones a la hora de escribir algunas palabras que son enmendadas con la sustitución de una letra por otra, así tendríamos «Vespacianus» que debe ser enmendado por «Vespasianus» o el caso de «Zebedei Collegii» que, según el autor, tendría que ser «Zebedoei collegio».

Asimismo, se indica en alguna ocasión la sustitución de una letra minúscula por la misma pero en mayúscula («donationis» por «Donationis» o «ricoshomes» por «Ricoshomes»). Otro caso sería cuando indica que se debe añadir una letra, como cuando dice que hay que escribir «supplicij» en vez de «suplicij». Sin embargo, hay casos en los que faltan palabras, como cuando delante de «quo autor» añade «ex», y otras veces que elimina una palabra entera y la modifica por completo, como por ejemplo cuando tacha «elucidantun y la sustituye por «perpenduntur». En otras ocasiones añadió palabras completas, quizás porque se habían olvidado de introducirlas o porque en el original no aparecían, caso de la añadidura de "purpura» en la tercera línea y de «et aliorum» casi al final después de "Regni» en el punto 19 del sumario.

No obstante, el caso más evidente de que el autor pudo reelaborar su texto es cuando vemos que modifica la siguiente frase: «Nobiles à Dibitibus Nobilium quo peculiare proprium esse donare ostenditurn, la cual reestructura para que pasase a ser: "Nobiles ac divites à Dibitibus. Nobilium proprium ac peculiare esse donare ostenditum. Vemos, por tanto, como Juan de Ibero sí que es posible que introdujese cambios y que no todas las erratas o fallos en la prueba de imprenta se deban achacar a una mala comprensión del latín por parte de los oficiales que trabajaban junto a Carlos de Labayen.

Ya en el folio 14v que sigue correspondiendo al Summaria se constatan errores muy similares a los evidenciados en la primera parte. Sin duda, hay numerosas erratas y fallos gramaticales que el autor señaló y enmendó rigurosamente. Primero sigue anotando con el símbolo ( | ) los espacios que deben añadirse para que no se junten dos palabras, caso de «leges $\mid$ tam» $\mathrm{o}$ "Navarrae|ex arbitrio». Después nos encontramos con la eliminación de alguna letra tachándola 
porque sobra, caso por ejemplo de "matutinam» en la que el autor tacha la última "m» para que se quedase "matutina», así como en la siguiente palabra en la que "surrectionem» se convierte en "surrectio». Junto a esto, se advierten equivocaciones a la hora de escribir algunas palabras que son enmendadas con la sustitución de una letra por otra, así tendríamos «sentencia» que debe ser enmendado por «sententia». Otro caso distinto sería cuando indica que se debe ańadir una letra, como cuando dice que hay que escribir «commissum» en vez de "comissum», o por ejemplo «Figueroa» y no "Figuroa», y en vez de "cum Do Ioanes» indica que debe decirse «cum Dominus Ioannes».

Sin embargo, hay casos en los que faltan palabras, como cuando en la segunda línea incorpora "ostondetur» y antes del número 31 del sumario añade "cum alys», así como al final del mismo al escribir la expresión «Finis». A su vez, otras veces elimina una palabra entera y la modifica por completo, como por ejemplo cuando tacha "referunt» y la sustituye encima de su puño y letra por "referuntur», así como «interpretantur» lo modifica por "exponuntur». En otras ocasiones, como se aprecia, modificó frases con la sustitución de varias palabras por otras, quizás porque el autor decidió modificar el sumario, ya que no se puede tratar en estos casos de errores en la composición. Así, por ejemplo, tendríamos en la primera línea la supresión de "populi iure etiam communi forum d. Regni» por "non solum jure d. Regni», así como otro caso que aparece al final del número 29 del sumario, donde la frase "per necessariam fore ostenditur» según Ibero se debía sustituir por «valesudinem per utile esse probatun. Por último, vemos también como Ibero introdujo otros cambios, caso de algún paréntesis que indicaba que no era necesario que se pusiese, tal y como expresa al margen en referencia al número 32 del summaria y otro que añadió por su cuenta manualmente en la primera línea.

Tras el sumario aparece el último pliego impreso en los folios 15r y 16v. En ambos no hay ninguna corrección manuscrita hecha por el autor, por lo que cabe pensar que se trataría de impresiones realizadas con posterioridad a las pruebas presentadas al autor dada la ausencia de correcciones pese a los errores gramaticales que se localizan en las dos. Esto último hace pensar que fueron composiciones tiradas justamente en el momento en que Juan de Ibero cayó enfermó y se suspendió la edición del Novus et Analyticus Commentarius, por lo que no fueron corregidas por el autor, aunque sí presentadas, como podemos apreciar, por Carlos de Labayen durante el pleito como prueba pericial de los trabajos que había desarrollado.

No obstante, llama la atención la mala factura de estos últimos folios, pues en el $15 \mathrm{r}$ se aprecia una falta de tinta en algunas partes, lo que pudo deberse a un mal reparto de la tinta o que al tratarse de una prueba no se empapó lo suficiente el molde para que la impresión fuese óptima. Si bien también pudo ocasionarse fruto de una mala nivelación del molde, dando como resultado esa imagen de mal acabado y borroso en ciertas partes. Después en el folio 16v lo que advertimos es que en la parte central aparecen algunas palabras y frases torcidas, como si hubiesen bailado los tipos a la hora de proceder a la impresión 


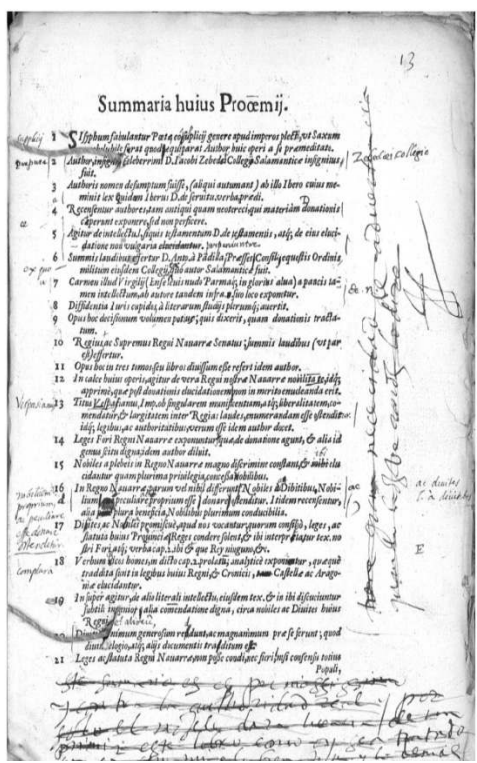

Imagen 8. - Summaria huius prooemij (AGN, Corte Mayor, proceso n. 330464 , fol. 13r)

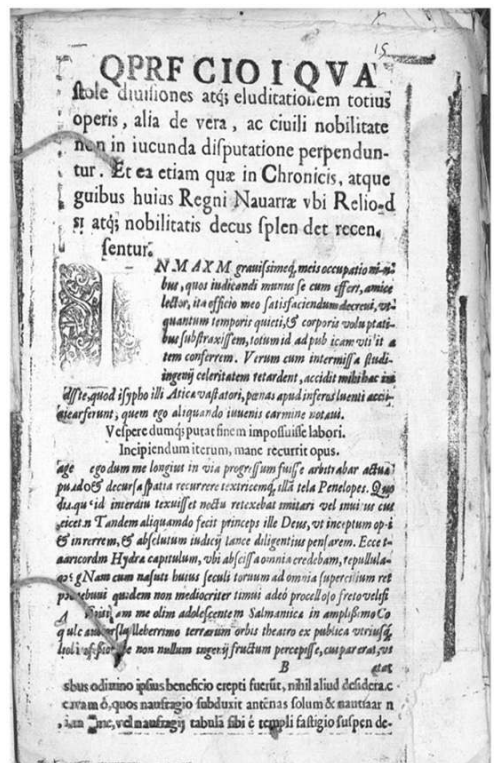

Imagen 10. - Texto

(AGN, Corte Mayor, proceso

n. 330464 , fol. 15 r)

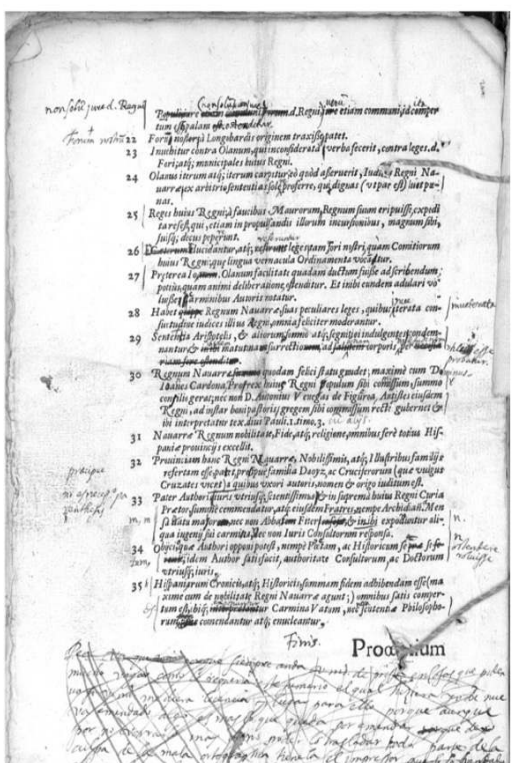

Imagen 9. - Summaria huius prooemij (AGN, Corte Mayor, proceso n. 330464 , fol. 14v)
Imagen 11. - Texto

(AGN, Corte Mayor, proceso n. 330464 , fol. 16v) 
de esta composición. Una vez más cabe pensar que este pésimo acabado pudo deberse única y exclusivamente a que se trataba de pliegos de prueba.

Una vez vistos los testimonios documentales que fueron presentados por Carlos de Labayen durante el pleito que mantuvo con Juan de Ibero cabe afirmar que los mismos constituyen una primera prueba destinada al corrector, en este caso el mismo autor que actuaba como editor, para su lectura y revisión porque nos encontramos ante dos hojas sueltas impresas solo por una cara (el recto) en el caso de la portada, y el resto son pliegos doblados una vez y conformados por dos hojas que estaban únicamente estampados por dos caras ( 1 recto y 2 verso), por lo que otras dos se dejaban en blanco (1 verso y 2 recto). Además, las estampaciones de dichos pliegos no siempre son consecutivas, por lo que esto viene a demostrar que con esta primera y única prueba que se conserva no se buscaba otra cosa que revisar el texto, sin tener el menor interés por comprobar la correspondencia de una página con la siguiente. Dicho esto, incluso cuando son impresiones consecutivas, caso del summaria, apreciamos como la primera parte del mismo se estampa en el 1 recto (folio $13 \mathrm{r}$ del proceso) de su correspondiente pliego y la segunda parte aparece en ese mismo pliego pero en la cara 2 verso (folio $14 \mathrm{v}$ del proceso), por lo que se ratificaría la mera intención de servir como prueba para la corrección del autor, pues si hubieran querido comprobar la correspondencia del mencionado sumario lo habrían impreso de forma correlativa.

Al margen de esto, centrándonos en el aspecto más formal de la corrección propiamente dicha lo que nos ha permitido constatar esta prueba de imprenta es la variada proporción y naturaleza de los errores detectados, pues en algunos casos se trata de erratas más relevantes o acusadas frente a otras en las que ni siquiera hay ninguna advertencia manuscrita hecha por el autor. Ese elevado número de enmiendas señaladas por Juan de Ibero nos hace pensar en el proceso de composición de aquellos pliegos, ya que solamente así podremos llegar a intuir los posibles motivos que ocasionaron las deficiencias detectadas por el autor durante la corrección de los mismos. Por desgracia, únicamente conocemos que durante la composición de esta prueba estaban en el taller de Labayen trabajando junto a él Diego de la Torre ${ }^{35}$, Domingo Hernández ${ }^{36}$ y Pedro de Berjes ${ }^{37}$. En total son cuatro personas distintas, aunque desconocemos

35. Se conocen algunos datos de este tipógrafo al que Delgado Casado cataloga como ambulante y del cual dice que no se sabe nada entre 1607 y 1615, si bien entre 1607 y 1609 lo debemos ubicar en Estella y Pamplona a tenor de las referencias obtenidas el pleito estudiado. Véase para conocer mejor a este impresor la obra de Juan Delgado Casado, Diccionario de impresores españoles: (siglos XV-XVII), Madrid, Arco Libros, 1996, t. II, pp. 676-677.

36. Poco sabemos de él, aunque debía de estar afincado en Zaragoza desde 1595 como así lo señala el estudio de Ángel San Vicente, Apuntes sobre libreros, impresores y libros localizados en Zaragoza entre 1545 y 1599. II. Los impresores, Zaragoza, Gobierno de Aragón, 2003, t. II, p. 70.

37. Pedro Berjes o Vergés, según Delgado Casado, aparece en 1624 como impresor en la ciudad de Zaragoza, por lo que muy posiblemente sea este mismo que encontramos en 1607 trabajando a las órdenes de Carlos de Labayen en Pamplona de forma esporádica. Si se quieren ampliar conocimientos sobre este impresos consúltese el trabajo de Juan Delgado Casado, Diccionario de impresores españoles: (siglos XV-XVII), Madrid, Arco Libros, 1996, t. I, pp. 361-362. 
quién actuó como componedor y quién hizo la labor de cajista. No obstante, lo que apreciamos es que mientras en la portada debieron tener una mayor libertad, en el resto del texto el carácter literario de la obra les otorgó una menor posibilidad de improvisar porque debían ceñirse al original manuscrito. Si bien constatamos que el latín debió de ser una traba a la hora de componer esta prueba, sobre todo en la parte del epigrama y del sumario porque los errores advertidos son, en muchas ocasiones, cuantiosos y de gran relevancia.

Un hecho que nos lleva a plantearnos dos hipótesis principales, pues parece que el original manuscrito no se interpretó bien por diversos problemas, caso de la mala caligrafía del autor, a lo que se añadiría que el encargado de componer las planchas no dominaba el latín y fruto de ello cometió tantas faltas ortográficas. Bien es cierto que es posible que algunas erratas tuviesen su origen en errores involuntarios del componedor al leer el origina ${ }^{38}$, aunque por las enmiendas detectadas cabe inclinarse más por una mala interpretación del texto unida a la falta de conocimientos en lengua latina. Qué duda cabe que el hecho de que la obra estuviese íntegramente en latín debía provocar en el cajista una mayor preocupación, o al menos atención, a la hora de preparar el texto.

Cabe afirmar, como hace Garza ${ }^{39}$, que el original se tomaba como modelo aunque ello no significa que fuera al pie de la letra, puesto que las pruebas conservadas muchas veces nos evidencian la posibilidad de encuadrar modificaciones hasta el último momento. Junto a ello, no debemos olvidar que las imperfecciones detectadas durante la fase de corrección pueden tener un origen didáctico fruto del desconocimiento o la escasa pericia en el manejo del latín, lo que habría provocado los innumerables errores que fueron advertidos por el autor.

Fruto de esta situación el propio Ibero, posiblemente preocupado, dejó al impresor dos claros mensajes tras corregir las pruebas que aparecen tachados en la parte final y en los márgenes de los folios $13 \mathrm{r}$ y $14 \mathrm{v}$. Respecto al sumario señaló que: "este sumario es perniossissimo y contra la autoridad real y por esto no se le dará licencia de imprimir este libro como así sea tratado consigo, mírelo bien». Exhortándole de forma clara: «y lo demás tiene gran necesidad de advertencia quando así veamos lo digo» ${ }^{40}$. Después escribió una dura advertencia final dirigida a Labayen, pues de su puño y letra dijo: "peor va que vino porque siempre anda v.md. de prisa en cosas que piden mucho vagar como le requería este sumario el cual hiciera yo de nuevo si v.md. me diera licencia y lugar para ello porque aunque va emendado algo es más lo que

38. Sobre esta cuestión véanse las apreciaciones de José Manuel Lucía Megías, «Escribir, componer, corregir, reeditar, leer (o las transformaciones textuales en la imprenta)», en A. Castillo Gómez, Libro y lectura en la Peninsula Ibérica y América (siglos XIII al XVIII), Salamanca, Junta de Castilla y León, 2003, p. 216; Trevor J. Dadson, «Entre componedores y correctores», en J. M. Lucía Megías, Imprenta, libros y lectura en la España del Quijote, Madrid, Ollero y Ramos, 2006, p. 231.

39. Sonia Garza Merino, op. cit., 2012, p. 131.

40. AGN, Tribunales Reales. Procesos, núm. 330464, fol. 13r. 
queda por emendar porque dexo por no borrarlo más y no poderlo trasladar todo». Es entonces cuando achacaba toda la culpa al mal hacer del tipógrafo, al afirmar: "parte de la culpa de la mala ortographia tienela el impresor que se le trasladó el original correcto, tiene poca ciencia de lo que es latín». Vemos, por tanto, como Ibero acusaba a Labayen de no tener muchos conocimientos de la lengua latina, lo que desde su punto de vista habría ocasionado tantos errores y malas interpretaciones en las pruebas corregidas. Por último, el autor señalaba que «acerca del estilo tenía que hablar con v.md. pero hoy no es posible por tenerme ocupado la obediencia y el reverendo provincial» ${ }^{41}$.

Lo que se hace evidente en este artículo es que el autor cuando además actuaba como editor mostraba un especial cuidado durante la fase de corrección de pruebas. Un celo que le llevó a invalidar numerosas palabras y corregir frases enteras, e incluso a reestructurar buena parte de los pliegos por el alto índice de erratas localizadas. Sin duda, el hecho de encontrarnos con erratas nos lleva enseguida a pensar en las causas de las mismas. Tradicionalmente se ha tendido a pensar que tanto los copistas como los componedores eran los principales culpables como consecuencia de malas lecturas, aunque también podía deberse a la dificultad por entender el original manuscrito o al empleo de palabras no conocidas por lo poco frecuentes en su uso. Igualmente, como expuso Moll ${ }^{42}$, otras de las posibles explicaciones fueron la mala distribución en el cajetín de determinados tipos, el error del componedor al confundir un tipo por otro o la colocación invertida de algunos tipos.

Todo ello explicaría muchas de las más que posibles causas que provocaron las múltiples enmiendas que introdujo Ibero en su texto, aunque además de las señaladas se han advertido dos más: los escasos conocimientos de latín que atesoraban Labayen y los oficiales que contrató para esta edición, así como el propio interés del autor por mejorar su texto dándole una mayor pulcritud al reemplazar en algunas ocasiones frases de cinco o seis palabras por otras totalmente distintas. En suma, la labor de corrección desempeñada por muchos autores no se limitaba tan solo a identificar los posibles errores que se habían ocasionado durante el traslado del original manuscrito al impreso en el taller de imprenta, sino que también buscaban pulir y mejorar su propio texto al enmendar expresiones y frases que ellos habían empleado en el original manuscrito y que después decidían sustituir para mejorar la calidad gramatical de su obra.

\section{Conclusiones}

El testimonio recuperado para este artículo nos habla de la época de la imprenta manual, de los modos y prácticas editoriales, y lo que es más importante, nos revela datos fundamentales para que seamos capaces de

41. AGN, Tribunales Reales. Procesos, núm. 330464, fol. 14v.

42. Jaime Moll, «La imprenta manual», en F. Rico, Imprenta y crítica textual en el Siglo de Oro, Valladolid, Universidad de Valladolid, 2001, p. 15. 
conocer mejor los entresijos del proceso de edición de textos durante el Siglo de Oro. Sin duda alguna, si queremos desentrañar los avatares editoriales de cualquier publicación no sólo debemos basarnos en el análisis material del texto en cuestión, sino que tendremos que sumar a ello - como sugirió Moll ${ }^{43}$ la inestimable ayuda que nos ofrecen todo tipo de rastros documentales de multitud de archivos. Solamente así seremos capaces de adentrarnos en diversos aspectos de la intrahistoria editorial que, a simple vista, se nos presentan indescifrables.

Como se ha indicado al principio de este trabajo, las pruebas de imprenta conservadas hasta la actualidad son más bien escasas, por lo que cuando aparece una debemos tratar de dar a conocer al público interesado en la Historia del Libro los datos que nos revela. En este caso hay suficientes evidencias como para pensar que nos encontramos ante uno de esos escasos testimonios destinados a la revisión y corrección de erratas. Tal y como ha sido advertido, se trata de estampaciones hechas en hojas sueltas y pliegos, en donde en las primeras se encuentran estampadas una cara del papel (el recto) y en los pliegos siempre lo están únicamente las caras externas (1 recto y 2 verso). Un hecho que demuestra que no había interés por comprobar la correspondencia entre el contenido de una página y el de la siguiente. Lo primordial era corregir las faltas de la composición, y en esta dirección cabe añadir que la proporción y naturaleza de los errores constatados en relación con la extensión de cada uno de los testimonios es variable, aunque en algunos casos de una considerable importancia.

La prueba de imprenta localizada ha sido, al mismo tiempo, la excusa perfecta para analizar el papel desempeńado por el autor-editor durante el Siglo de Oro. Sabíamos que una de las principales preocupaciones de cualquier autor, como expuso Lucía Megías ${ }^{44}$, fue que sus textos se imprimiesen sin erratas, por lo que muchas veces tuvieron que actuar como correctores para mitigar los posibles errores detectados. Una práctica que ya había sido señalada, entre otros, por Blecua ${ }^{45}$, Bouza ${ }^{46}$ o Dadson ${ }^{47}$, y que en este caso vuelve a ser puesta de manifiesto. No obstante, gracias a este estudio hemos constatado que su papel durante esta fase no se limitó únicamente a comprobar y subsanar las erratas localizadas, sino que también cabía la posibilidad de introducir variaciones en el texto de cierta consideración ${ }^{48}$.

\footnotetext{
43. Ibid., p. 27.

44. José Manuel Lucía Megías, Aqui se imprimen libros. La imprenta en la época del Quijote, Madrid, Ollero y Ramos, 2005, p. 103.

45. Alberto Blecua, Manual de critica textual, Madrid, Castalia, 1983, p. 173.

46. Fernando Bouza, «Para qué imprimir. De autores, público, impresores y manuscritos en el Siglo de Oro», Cuadernos de Historia Moderna, 18, 1997, p. 39.

47. Trevor J. Dadson, "El autor, la imprenta y la corrección de pruebas en el siglo XVII», El Crotalón. Anuario de Filología Española, 1, 1984, p. 1067.

48. Estas variaciones surgirían como consecuencia de revisiones exhaustivas por parte de los autores. Véase Trevor J. Dadson, op. cit., 2006, p. 241.
} 
De este modo, se ha evidenciado en algunas ocasiones el papel que jugaba el autor en estos casos, ya que, además de corregir su propio texto, lo actualizaba y mejoraba para dotar a su obra de una mayor calidad tanto técnica como estética en el lenguaje empleado. Lo cierto es que Juan de Ibero dedicó tiempo a mejorar la calidad gramatical de su texto al introducir modificaciones en palabras o frases por considerar que en el original manuscrito se había equivocado o bien porque estimaba que quedaba mejor decirlo de otra manera. Un dato del que inferimos la especial preocupación que manifestaron los autores-editores por publicar un buen producto editorial, no solo fijándose en la calidad material del libro (tipo de papel, tintas, tipografía empleada, etc.), sino también en la pulcritud gramatical del mismo.

En definitiva, el presente estudio viene a sumarse a los que le han precedido en estas lides en la idea de reconstruir fielmente los avatares que cualquier edición tuvo que afrontar antes de ser comercializada en plena Edad Moderna. Qué duda cabe que entre los procesos más relevantes se encontraba la corrección de pruebas. Una etapa que nos habla de multitud de aspectos de un libro, no ya sólo materiales o formales sino también relativos al papel desempeñado por impresores y autores, lo que permite tener un mejor conocimiento de la intrahistoria editorial de las obras publicadas (y de las no publicadas finalmente) entre los siglos XVI y XVII. Asimismo, en nuestro caso debemos resaltar que al tratarse de una edición fallida la prueba de imprenta conservada del Novus et Analyticus Commentarius juega un papel clave, pues nos ha permitido conocer un texto desconocido hasta ahora que viene a enriquecer un poco más la historia del libro y de la imprenta en el Reino de Navarra. 
